\title{
Improving Health Services
}

[LS blogs.Ise.ac.uk/healthandsocialcare/2013/11/13/improving-health-services/

$13 / 11 / 2013$

\section{by Walter Holland, LSE Health}

The introduction of scientific principles into government decision-making began with the publication of the Haldane Report in 1918.

Haldane believed that research should play a key role in government and that it should be an integral part of the machinery of government. Although the Medical Research Committee (later Medical Research Council) played a key role in the investigation of problems arising from war conditions in the First World War it did not play a central role in the development of applied health services research. Its major contribution was to sustain and develop basic research crucial to the development of knowledge about the mechanisms and treatment of disease.

With the establishment of the NHS in 1948 the Minister of Health was given specific powers and responsibilities for pursuing a programme of research to support its needs. It was not, however, until the 1960s that the Department of Health began to commission substantial amounts of research. The book "Improving Health Services" traces the development of this research. At the beginning there was tension between the old-established Medical Research Council and the newer, much more applied, research instigated by the Department of Health. This tension was not helped, in the early years, by the government's emphasis on the priorities of research that could support practical application rather than only increase in knowledge-based research (Rothschild principles). Over time a "modus vivendi" was achieved.

The development and support of health services research by the Department of Health has been subject to difficulties. Health Services Research is fundamentally a political matter. Civil servants had, at first, problems in accepting that research could question policy decisions. Politicians have had difficulties in appreciating that research could uncover problems and inadequacies in the NHS. In the late 1980s a House of Lords Select Committee commented on these problems but also emphasised the importance of this type of research but that the resources available were inadequate and that leadership of the research needed to have more input into central decision-making. Clinicians, and their supporters, sometimes resisted both the investigation of current practices as well as the application of findings.

In spite of these obstacles great advances have been made. The volume illustrates how research has helped to develop and apply knowledge to assess health service needs, introduce new effective methods of treatment and prevention, develop indicators of health service quality and methods of surveillance of health, as well as the organisation of specific services, e.g. general practice.

Recommendations on methods of working and the organisation of the research are given, with particular emphasis on the need for multidisciplinary working and close co-operation and contact between those concerned with service delivery and the researchers. The relationships of those involved with research and the commissioners of research are discussed.

There are now many more researchers from all disciplines involved in this type of research and their standing has improved greatly. It is, however, disappointing that many of the lessons learnt are not used more. Several major policy decisions e.g. the recent reorganisation of the NHS, the promotion of polyclinics and the promotion of "health checks" have not been subjected to rigorous scientific scrutiny. In spite of the increase in trained researchers, government and the NHS, continues to utilise management consultants, who have often little expertise in the field. These are far more costly, but, of course, far more likely to succumb to political pressure. Many health policy decisions are now based on theoretical complex mathematical modelling because of the availability of much more 
administrative data subject to indeterminate errors and assumptions rather than the collection of field data for a defined purpose, as was common in the past.

This is understandable if it is accepted that the most important pre-requisite is to satisfy immediate political imperatives, rather than be constrained by the need to undertake reliable, valid research, which takes time.

It is to be hoped that the current political media-inspired and media-stoked frenzy will abate and that once again we will fund and take heed of properly planned research. 